\title{
Distinguishing between Presynaptic and Postsynaptic Mechanisms of Short-Term Depression during Action Potential Trains
}

\author{
Adrian Y. C. Wong, ${ }^{1}$ Bruce P. Graham, ${ }^{2}$ Brian Billups, ${ }^{1}$ and Ian D. Forsythe ${ }^{1}$ \\ ${ }^{1}$ Department of Cell Physiology and Pharmacology, University of Leicester, Leicester, LE1 9HN, United Kingdom, and ${ }^{2}$ Department of Computing Science \\ and Mathematics, University of Stirling, Stirling, FK9 4LA, United Kingdom
}

\begin{abstract}
Short-term facilitation and depression have a profound influence on transmission at many glutamatergic synapses, particularly during trains of stimuli. A major component of these processes is postsynaptic receptor desensitization. Both presynaptic and postsynaptic mechanisms can contribute to synaptic efficacy, but it is often difficult to define their respective contributions. Blockers of desensitization such as cyclothiazide (CTZ) can be used, but many of these drugs have nonspecific effects on transmitter release, complicating attempts to define synaptic effectiveness under physiological conditions. We describe and validate a new method to minimize desensitization during trains of synaptic stimuli that is based on the low-affinity competitive glutamate receptor antagonists $\gamma$-Dglutamylglycine or kynurenic acid. A computational model of AMPA receptor kinetics shows that the mechanism can be accounted for by simple competitive antagonism of AMPA receptors, where the rapid off-rate of the antagonist permits re-equilibration between blocked and unblocked pools during the interstimulus interval. Our results at the calyx of Held show that desensitization makes little contribution to synaptic depression at frequencies below $10 \mathrm{~Hz}$, but at higher frequencies it makes an important contribution, with accumulating desensitization masking short-term facilitation and causing an underestimation of quantal content. This novel method of protection from desensitization is compatible with physiological studies but cannot be used in conjunction with CTZ. Although presynaptic vesicle depletion makes the dominant contribution to short-term depression, our results show that AMPA receptor desensitization contributes to the depression at auditory synapses after hearing onset and in a frequency-dependent manner.
\end{abstract}

Key words: desensitization; AMPA receptor; short-term depression; cyclothiazide; calyx of Held; excitatory synaptic transmission; auditory processing; voltage clamp

\section{Introduction}

Information in the nervous system is encoded as patterned bursts of action potentials that trigger synaptic transmitter release and generate postsynaptic responses in receiving neurons. The efficacy of an EPSP in generating an action potential (AP) not only depends on postsynaptic integration with voltage-gated conductances but is contingent on the recent history of release from that synapse and on spontaneous activity (Fortune and Rose, 2001; Fuhrmann et al., 2002). The extent to which presynaptic and postsynaptic mechanisms interact to generate short-term changes in synaptic magnitude is a long-standing problem, because both are interrelated; for instance, high release rates enhance vesicle depletion and promote desensitization of postsynaptic receptors.

Many central synapses use glutamate as the transmitter, acting at postsynaptic AMPA and NMDA receptors (Forsythe and Westbrook, 1988). AMPA receptors show rapid desensitization and slower recovery, thus permitting accumulation of desensitization during repetitive activity (Trussell et al., 1988; Edmonds et al., 1995; Jones and Westbrook, 1996). Different AMPA receptor subtypes show a range of deactivation and desensitization rates (Mosbacher et

Received Feb. 5, 2003; revised March 25, 2003; accepted March 28, 2003.

This work was funded by the Wellcome Trust. Thanks to Alasdair Gibb and Laurence Trussell for comments on this manuscript and to the staff of the mechanical and electrical workshop at the University of Leicester for their technical expertise.

Correspondence should be addressed to Prof. lan D. Forsythe, Department of Cell Physiology and Pharmacology, University of Leicester, P.0. Box 138, University Road, Leicester, LE1 9HN, UK. E-mail: idf@le.ac.uk. Copyright $\odot 2003$ Society for Neuroscience $\quad$ 0270-6474/03/234868-11\$15.00/0 al., 1994), with "flop" splice variants showing faster kinetics but lower sensitivity to block of desensitization by cyclothiazide (CTZ) (Partin et al., 1994, 1996). Desensitization occurs at lower glutamate concentrations than for receptor activation and can completely block the current, with desensitized receptors having enhanced glutamate affinity (Mayer and Vyklicky, 1989). Glutamate binds to each of the four channel subunits (Rosenmund et al., 1998; Robert et al., 2001), causing channel opening through rearrangement of the interface at dimers formed between the four extracellular S1/S2 glutamate binding domains (Sun et al., 2002). Desensitization occurs as a further rearrangement of this dimer interface, disengaging the ligandbinding region from the channel gate, a process that is blocked by CTZ (Sun et al., 2002). CTZ also has nonspecific presynaptic actions (Barnes-Davies and Forsythe, 1995; Diamond and Jahr, 1995; Bellingham and Walmsley, 1999; Ishikawa and Takahashi, 2001) that render it unsuitable for many synaptic studies.

Our purpose is to define the contribution of AMPA receptor desensitization to short-term depression during physiological trains of stimuli. Although fundamental for the interpretation of transmission, this question is difficult to disentangle from other modulatory influences. We have used the calyx of Held, where the EPSC is predominantly mediated by AMPA receptors (BarnesDavies and Forsythe, 1995; Taschenberger and von Gersdorff, 2000). During a stimulus train, the EPSC declines to less than half initial amplitudes (Iwasaki and Takahashi, 2001). Some reports have suggested that desensitization makes little contribution to short-term depression within 10 stimuli (Wang and Kaczmarek, 
1998; Hjelmstad et al., 1999), but biophysical studies suggest otherwise (Raman and Trussell, 1995; Otis et al., 1996). We resolve this issue via an alternative approach using competitive glutamate antagonists with fast kinetics that sequester a proportion of subsynaptic receptors into blocked states, thereby protecting them from desensitization (Wong et al., 2001). We show that desensitization contributes to short-term depression in a frequency-dependent manner, making little contribution at frequencies up to $10 \mathrm{~Hz}$ but accounting for up to half of the depression at higher frequencies.

\section{Materials and Methods}

Preparation of brain slices. Lister-Hooded rats (aged 10-13 d old) were killed by decapitation, and brainstem slices containing the superior olivary complex (SOC) were prepared as described previously (BarnesDavies and Forsythe, 1995). Briefly, 250- $\mu$ m-thick transverse slices of SOC containing the medial nucleus of the trapezoid body (MNTB) were cut in a low-sodium artificial CSF (aCSF) solution at a temperature of $\sim 0^{\circ} \mathrm{C}$. Slices were incubated after slicing in normal aCSF at $37^{\circ} \mathrm{C}$. After 1 $\mathrm{hr}$, the chamber was removed from the water bath, and slices were left at room temperature. The composition of the normal aCSF was (in $\mathrm{mm}$ ): $125 \mathrm{NaCl}, 2.5 \mathrm{KCl}, 26 \mathrm{NaHCO}_{3}, 10$ glucose, $1.25 \mathrm{NaH}_{2} \mathrm{PO}_{4}, 2$ sodium pyruvate, 3 myo-inositol, $2 \mathrm{CaCl}_{2}, 1 \mathrm{MgCl}_{2}, 0.5$ ascorbic acid. The $\mathrm{pH}$ was 7.4 when bubbled with $95 \% \mathrm{O}_{2} / 5 \% \mathrm{CO}_{2}$. For the low $\mathrm{Na}^{+}$aCSF, 250 mM sucrose was substituted for $\mathrm{NaCl}$, and $\mathrm{CaCl}_{2}$ and $\mathrm{MgCl}_{2}$ concentrations were 0.1 and $4 \mathrm{~mm}$, respectively.

Electrophysiology and imaging. Whole-cell patch-clamp recordings were made from postsynaptic MNTB neurons using an Axopatch 200A amplifier (Axon Instruments, Foster City, CA). Patch pipettes were pulled in a twostage vertical pipette puller (PP-83, Narishige, Tokyo, Japan) from thickwalled borosilicate glass capillaries containing an internal filament (GC150F-7.5, outer diameter $1.5 \mathrm{~mm}$, inner diameter $0.86 \mathrm{~mm}$; Clark Electromedical, Reading, UK). Pipettes had a final resistance of $\sim 8 \mathrm{M} \Omega$ when filled with an internal solution containing (in mM): $110 \mathrm{CsCl}, 40 \mathrm{HEPES}, 0.5$ EGTA, 12 phosphocreatine, 5 QX-314 (pH adjusted to 7.3 with CsOH).

Cells were visualized using a Zeiss Axioskop fitted with DIC optics and an Olympus LUMPlanFL $60 \times 0.9$ numerical aperture objective. Synaptic connections were detected using a calcium imaging technique as described previously (Billups et al., 2002). Briefly, MNTB neurons were loaded with $7 \mu \mathrm{M}$ Fura-2 AM for $5 \mathrm{~min}$. A single image at $380 \mathrm{~nm}$ was taken using a Photometrics CoolSnap fx camera, and a "region of interest" was drawn around loaded cells using Metaflour imaging software (version 4.01, Universal Imaging Corporation, West Chester, PA). Connected cells were identified by imaging for $100 \mathrm{msec}$ at a frequency of $3 \mathrm{~Hz}$ at $380 \mathrm{~nm}$ using a xenon arc lamp controlled via a Cairn Optoscan (Cairn Instruments, Faversham, UK). A cell with an intact synaptic connection produced a decrease in the $380 \mathrm{~nm}$ signal after a short train of three stimuli $30 \mathrm{msec}$ apart at a stimulus intensity of $8 \mathrm{~V}$ or a single $200 \mathrm{~Hz}$ train of $1 \mathrm{sec}$ duration. Cells were stimulated using an extracellular bipolar platinum electrode placed on the midline. Stimulus trains were delivered through a DS2 Isolated Stimulator (Digitimer, Welwyn Garden City, UK) and generated using a Master-8 programmable pulse generator (AMPI, Jerusalem, Israel). A bright-field photograph was then taken using Metafluor, and the connected cell was located and then patched under the microscope.

Experiments were performed at 26 or $37^{\circ} \mathrm{C}$ (as noted in Results). MNTB neurons were voltage-clamped at a holding potential of $-60 \mathrm{mV}$. Cells with intact synaptic connections were stimulated with trains of stimuli at 10, 20, 50, 100, and occasionally $200 \mathrm{~Hz}$. Trains were of 1 or 2 sec duration and repeated at $30 \mathrm{sec}$ or 1 min intervals, respectively. Five trains were given at each stimulus frequency. Although competitive antagonists reduced EPSC amplitude by $\sim 80 \%$, averaging of multiple traces provides an adequate signal-to-noise ratio even when recording small EPSCs. EPSCs were filtered at $5 \mathrm{kHz}$ and sampled at $20 \mathrm{kHz}$; series resistances $(<20 \mathrm{M} \Omega)$ were compensated by $75 \%$. Experiments were performed in the presence of $2 \mathrm{~mm}$ calcium (except where stated otherwise), and drugs were applied by bath perfusion in the aCSF. All recordings were made in the presence of $10 \mu \mathrm{M}$ bicuculline, $1 \mu \mathrm{M}$ strychnine, $40 \mu \mathrm{M} \mathrm{D}$-(-)2-amino-5-phosphonopentanoic acid, and $10 \mu \mathrm{M}$
(5S, 10R)-+-5-methyl-10,11-dihydro-5H-dibenzo[a,d]cyclohepten-5,10imine maleate to block GABA, glycine, and NMDA receptors, respectively. Antagonists, including $\gamma$-D-glutamylglycine $(\gamma$-DGG) were purchased from Tocris Cookson, (Bristol, UK). Other chemicals and drugs were obtained from Sigma (Poole, UK).

All data were acquired using the Clampex 8.1 (Axon Instruments). Analysis of EPSC amplitudes and blanking of stimulus artifacts were performed using Excel (Microsoft, Seattle, WA), and depression kinetics of the train and decay times of individual EPSCs were analyzed using Clampfit 8.1 (Axon Instruments). Data are expressed as mean \pm SEM from at least four separate cells (mean five sweeps at each frequency per cell).

Modeling. The model consists of 500 independent active zones each with zero, one, or more readily releasable vesicles (Graham et al., 2001). The arrival of a presynaptic action potential causes a transient $(0.2 \mathrm{msec})$ increase in the vesicle release probability. The amplitude of the transient is scaled to give an initial release probability of 0.17 per vesicle. This amplitude is incremented at each action potential to give an effective facilitation of the probability of release of 0.05 , with the increment decaying to zero with a time constant of $100 \mathrm{msec}$ between action potentials. Release probability between action potentials is zero, and multiple vesicles can be released during a single action potential. Release of a vesicle generates a square wave pulse of transmitter in the synaptic cleft $([\mathrm{T}]=1 \mathrm{~mm}$ for $1 \mathrm{msec}$ after vesicle release) that drives an AMPA receptor-mediated current in the postsynaptic cell. A different population of receptors is assumed for each active zone, and no interaction between zones is included. Vesicles are replenished at active zones by an activity-dependent rate constant from a large reserve pool. The model of AMPA receptor kinetics includes a number of closed states, fast and slow open states, and two desensitized states based on the one derived by Raman and Trussell $(1992,1995)$. Binding of $\gamma$-DGG to AMPA receptors was best modeled by three blocked states, with rate constants based on the Diamond and Jahr (1997) and Wadiche and Jahr (2001) models. Blocking rate constants were set to match measured reductions in EPSC amplitude for different doses of $\gamma$-DGG. The rate constants for the AMPA response are set to give a fast EPSC with significant desensitization. AMPA receptor parameters are as follows: $R_{\mathrm{b}}=13 / \mathrm{mM}-\mathrm{msec}$, $R_{\mathrm{u}}{ }^{1}=6 / \mathrm{msec}, R_{\mathrm{u}}{ }^{2}=12 / \mathrm{msec}, R_{\mathrm{o}}{ }^{1}=60 / \mathrm{msec}, R_{\mathrm{c}}{ }^{1}=3 / \mathrm{msec}, R_{\mathrm{o}}{ }^{2}=$ $3 / \mathrm{msec}, R_{\mathrm{c}}{ }^{2}=0.35 / \mathrm{msec}, R_{\mathrm{d}}{ }^{1}=6 / \mathrm{msec}, R_{\mathrm{r}}{ }^{1}=0.02 / \mathrm{msec}, R_{\mathrm{d}}{ }^{2}=10 /$ msec, $R_{\mathrm{r}}{ }^{2}=0.02 / \mathrm{msec}, R_{\mathrm{d}}{ }^{21}=6 / \mathrm{msec}$; AMPA receptor blocking: $R_{\mathrm{bl}}{ }^{0}=$ $70 / \mathrm{mm}-\mathrm{msec}, R_{\mathrm{ub}}{ }^{0}=6 / \mathrm{msec}, R_{\mathrm{bl}}{ }^{1}=35 / \mathrm{mm}-\mathrm{msec}, R_{\mathrm{ub}}{ }^{1}=6 / \mathrm{msec}$, $R_{\mathrm{bl}}{ }^{01}=13 / \mathrm{mm}-\mathrm{msec}, R_{\mathrm{bl}}{ }^{10}=6 / \mathrm{msec},{R_{\mathrm{bl}}}^{2}=30 / \mathrm{mm}-\mathrm{msec}, R_{\mathrm{ub}}{ }^{2}=$ $12 / \mathrm{msec}$, driven by the steady-state application of $\gamma$-DGG. Only a single blocked state was necessary to model the application of 2,3-dihydroxy6-nitro-7-sulfamoyl-benzo(f)quinoxaline (NBQX), with $R_{\mathrm{bl}}=0.28$ / mM-msec, $R_{\mathrm{ub}}=0.000003 / \mathrm{msec}$. This is consistent with Schild analysis, suggesting that NBQX blocks either at a single site or on multiple identical but independent agonist binding sites on both glutamate receptor (GluR) 4 homomer and GluR2/4 subunit heteromers (Stein et al., 1992). At each active zone, the vesicle arrival rate from the reserve pool is $1.8 / \mathrm{sec}$ at $10 \mathrm{~Hz}$ and $17 / \mathrm{sec}$ at $50 \mathrm{~Hz}$; background removal from the release pool is $0.2 / \mathrm{sec}$. Each active zone initially contains five readily releasable vesicles. The model was implemented using the NEURON simulation package (Hines and Carnevale, 1997).

Statistics. Data were analyzed using a two-tailed, paired Student's $t$ test, and a $p$ value of $<0.05$ was considered statistically significant.

\section{Results}

Trapezoid body inputs to MNTB neurons were stimulated at frequencies between 10 and $200 \mathrm{~Hz}$ in aCSF containing $2 \mathrm{~mm}$ $\left[\mathrm{Ca}^{2+}\right]$. Calyceal synaptic currents had magnitudes in excess of 1 $\mathrm{nA}$ and a decay time constant $>2 \mathrm{msec}$ (Fig. $1 A$ ). Stimulus trains lasting 1 or $2 \mathrm{sec}$ generated EPSCs that declined in magnitude until a near steady-state amplitude was achieved. EPSCs were then relatively stable in size throughout the remainder of the train (Fig. $1 B$ ). The major part of depression occurred in the first 10 EPSCs of each train at all stimulus frequencies tested. Repetitions of $2 \mathrm{sec}$ trains were at intervals of $1 \mathrm{~min}$, and $1 \mathrm{sec}$ trains were at $0.5 \mathrm{~min}$ intervals. 
A

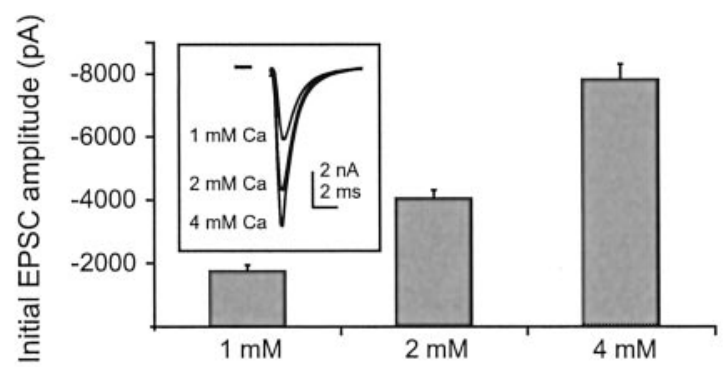

B

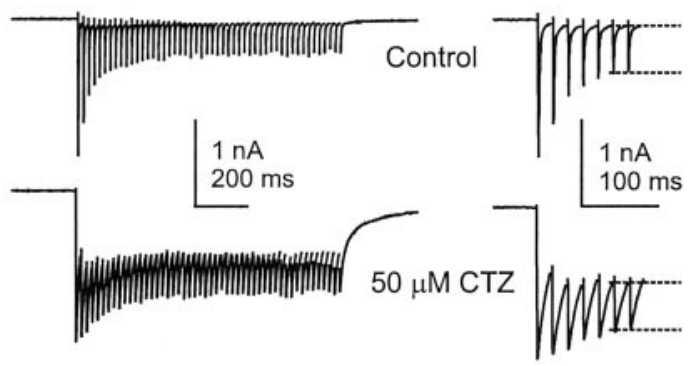

C

Time (s)
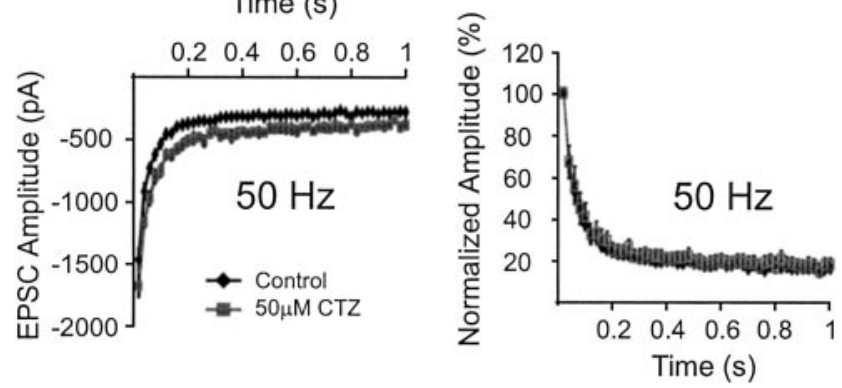

Figure 1. Short-term depression at the calyx of Held. A, Transmission is not saturated because raised calcium increases EPSC amplitude. Initial EPSC amplitude is plotted with $\left[\mathrm{Ca}^{2+}\right]_{0}$ of $1(n=4), 2(n=12)$, and $4 \mathrm{~mm}(n=4)$. Inset shows the effect of changing calcium concentration on the amplitude of a single EPSC; traces are means of 10 sweeps at each calcium concentration. B, Short-term depression generated by a 1 sec train at $50 \mathrm{~Hz}$ (left) with the first seven EPSCs expanded (right); top trace, control; bottom trace, during perfusion with $50 \mu \mathrm{m}$ CTZ. Dotted lines indicate measured EPSC amplitude (on the right); note the apparent summation in the presence of CTZ. Stimulus artifacts have been blanked for clarity. C, Average EPSC amplitude ( $n=4$ cells) in the presence (gray squares) and absence (black diamonds) of $50 \mu \mathrm{m}$ CTZ. D, Normalized EPSC amplitude expressed as a percentage of initial EPSC amplitude in the presence (gray squares) and absence (black diamonds) of $50 \mu \mathrm{m} \mathrm{CTZ.}$

\section{Postsynaptic responses are not saturated}

Under control conditions, raising the extracellular calcium concentration led to a concomitant increase in EPSC amplitude (Fig. $1 A)$ confirming that the postsynaptic response was not saturated. The mean first EPSC amplitude was $1.7 \pm 0.2 \mathrm{nA}$ in $1 \mathrm{mM} \mathrm{Ca}^{2+}$, $4.0 \pm 0.3 \mathrm{nA}$ in $2 \mathrm{mM} \mathrm{Ca}^{2+}$, and $7.8 \pm 0.5 \mathrm{nA}$ in $4 \mathrm{mM} \mathrm{Ca}^{2+}(n=$ 4) and was of similar amplitude across the range of stimulus frequencies tested. The onset rate of short-term depression during a $2 \mathrm{sec}$ train in $2 \mathrm{mM} \mathrm{Ca}^{2+}$ was approximated by a single exponential decay with a time constant of $164 \pm 75 \mathrm{msec}$ at $10 \mathrm{~Hz}$ and $112 \pm 13 \mathrm{msec}$ at $20 \mathrm{~Hz}(n=16)$. Higher stimulus rates showed a double exponential depression with fast time constants of $27 \pm 4.3 \mathrm{msec}$ at $50 \mathrm{~Hz}$ and $17 \pm 3.0 \mathrm{msec}$ at $100 \mathrm{~Hz}$; slow time
Table 1. Effect of $4 \mathrm{~mm} \gamma$-DGG on EPSC trains

\begin{tabular}{llllll}
\hline & Control & & & \multicolumn{2}{l}{$4 \mathrm{~mm} \gamma$-DGG } \\
\cline { 2 - 3 } \cline { 5 - 6 } Frequency (Hz) & $\mathrm{EPSC}_{\text {last }} / \mathrm{EPSC}_{1}$ & $\mathrm{EPSC}_{2} / \mathrm{EPSC}_{1}$ & & $\mathrm{EPSC}_{\text {last }} / \mathrm{EPSC}_{1}$ & $\mathrm{EPSC}_{2} / \mathrm{EPSC}_{1}$ \\
\hline 10 & $38 \pm 4.9$ & $89 \pm 4.5$ & & $43 \pm 5.1$ & $82 \pm 5.1$ \\
20 & $25 \pm 3.8$ & $89 \pm 4.9$ & & $62 \pm 10$ & $117 \pm 30$ \\
50 & $22 \pm 3.8$ & $70 \pm 9.2$ & & $49 \pm 8.7$ & $112 \pm 9.7$ \\
100 & $11 \pm 2.4$ & $58 \pm 11$ & & $24 \pm 4.8$ & $84 \pm 20$ \\
\hline
\end{tabular}

Data are mean \pm SEM of four different cells at all frequencies before and during bath application of $4 \mathrm{mM} \gamma$-DGG

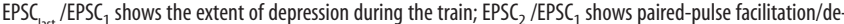
pression. $\gamma$-DGG increases the EPSC $C_{\text {last }} / E P S C_{1}$ and the paired-pulse ratio at all frequencies $>10 \mathrm{~Hz}$.

constants were variable, being $278 \pm 171 \mathrm{msec}(18 \pm 6.3 \%)$ and $420 \pm 102 \mathrm{msec}(6.8 \pm 2.3 \%)$, respectively $(n=16)$. In addition, there was a frequency-dependent increase in the amount of depression, measured as the steady-state amplitude at the end of the train (Table 1). These results indicate that short-term depression increased in a frequency-dependent manner and confirms that the AMPA receptor-mediated response is not saturated at physiological calcium concentrations ( $2 \mathrm{~mm} ; p>0.05)$.

\section{Cyclothiazide has little effect on synaptic depression}

Bath application of cyclothiazide, a blocker of AMPA receptor desensitization (Bertolino et al., 1993; Patneau et al., 1993; Trussell et al., 1993), increased EPSC amplitude and slowed the EPSC decay time (Barnes-Davies and Forsythe, 1995), resulting in summation of sequential EPSCs during a $50 \mathrm{~Hz}$ train (Fig. $1 B$ ). The short-term depression of EPSC amplitude was measured as the relative increase from baseline rather than the absolute peak current magnitude (Fig. $1 \mathrm{~B}$, between the dotted lines). Steadystate EPSC amplitude, as a percentage of the first EPSC, changed on application of $50 \mu \mathrm{M} \mathrm{CTZ}$ from $38 \pm 4.3$ to $34 \pm 3.1 \%$; $36 \pm 5.9$ to $37 \pm 1.1 \% ; 21 \pm 1.6$ to $23 \pm 3.1 \%$; and $13 \pm 1.5$ to $9.2 \pm 1.8 \%$ (n $\geq 4$ in each case) over frequencies from $10,20,50$, and $100 \mathrm{~Hz}$, respectively. The effect of CTZ on the EPSC amplitude during a 50 $\mathrm{Hz}$ train is plotted in Figure 1, $C$ and $D$. There was no significant effect $(p>0.05)$ of CTZ on the EPSC depression at any stimulus frequency, which has been previously interpreted as indicating that desensitization makes no contribution to short-term depression. However, CTZ is much less effective at AMPA receptor subunits containing the flop cassette, so an alternative hypothesis is that CTZ may not prevent desensitization during repetitive stimulation.

\section{Fast competitive antagonists can minimize desensitization}

Because of these doubts we have taken an alternative strategy to minimize desensitization, on the basis of the idea that a competitive antagonist can be used to sequester subsynaptic receptors into blocked states (from which channel kinetics do not favor desensitization). This strategy will minimize desensitization if the antagonist has rapid kinetics by allowing re-equilibration of blocked and unblocked receptors between stimuli. Therefore, only a small proportion of the receptors are activated by agonist and proceed into desensitized states, because transitions to the desensitized state require initial binding of ligand (Colquhoun et al., 1992; Otis et al., 1996). Rapid re-equilibration of the unblocked receptors with the much larger pool of blocked receptors means that each sequential agonist application (EPSC) is mediated by different receptors, and hence the impact of desensitization on EPSC amplitude is substantially blocked.

Two such antagonists have the required fast kinetics: $\gamma$-DGG (Wadiche and Jahr, 2001) and kynurenic acid (KYN) (Diamond and Jahr, 1997; Weber et al., 2001). Application of $4 \mathrm{~mm} \gamma$-DGG reduced first EPSC amplitude by an average of $81 \pm 6.8 \%(n=4)$ as shown in Figure $2 A i$. EPSC decay time courses were fit by a 
double exponential with a fast time constant of $0.92 \pm 0.07 \mathrm{msec}$ (relative contribution $75 \pm 2.5 \%$ ) in control conditions and $1.07 \pm 0.09 \mathrm{msec}(78 \pm 5.6 \%)$ in $4 \mathrm{~mm} \gamma-\mathrm{DGG}(p>0.05 ; n=$ $10)$. The magnitude of the slow time constant was $6.98 \pm 0.5$ and $7.86 \pm 1.22 \mathrm{msec}$, respectively $(p>0.05 ; n=10)$. There was a small but significant slowing in the EPSC $10-90 \%$ rise time in the presence of $\gamma$-DGG, from $0.40 \pm 0.01 \mathrm{msec}$ in control conditions to $0.50 \pm 0.02 \mathrm{msec}$ in $4 \mathrm{~mm} \gamma$-DGG (Fig. 2 Aii) $(p<0.05$; $n=10)$.

The EPSC amplitudes in the train were measured in the presence of $\gamma$-DGG and normalized to the amplitude of the first EPSC in control conditions from the same cell. The impact of desensitization was then examined by comparing the relative amplitude of each subsequent EPSC. The procedure is illustrated in Figure $2 B-D$ for trains of EPSCs evoked at a frequency of $50 \mathrm{~Hz}$ in two different MNTB neurons. On the left is an EPSC that exhibited high initial release probability with profound depression, and on the right are similar data from another calyx/MNTB synapse with a lower release probability and less depression. The control EPSC trains for two different cells are shown in Figure $2 B$. Figure $2 C$ shows the response from the same neurons in the presence of 4 mM $\gamma$-DGG. At the bottom, the $\gamma$-DGG trace is shown scaled to the amplitude of the first control EPSC of the train (Fig. $2 D$ ). This procedure corrects for the simple competitive action of $\gamma$-DGG on the EPSC so that the proportional change of the normalized EPSC amplitude against control EPSC amplitude gives an indication of the extent of depression caused by desensitization.

The EPSC trains from both MNTB neurons show qualitative differences compatible with reduction of desensitization in the presence of $\gamma$-DGG: after the first EPSC (Fig. 2D) there is a relative increase in the amplitude of each EPSC compared with the same EPSC in the control train (Fig. $2 B$ ). In the right-hand cell (Fig. 2Dii), this increase is sufficient to generate facilitated responses from second to eighth stimuli (i.e., EPSCs are greater than the first EPSC in the train), whereas depression predominated in the control data (Fig. $2 \mathrm{Bii}$ ). In addition, the relative magnitude of the steady-state responses (those responses at the end of the train) was larger than those recorded under control conditions in both cells, indicating that the amount of depression during the train is reduced by $\gamma$-DGG.

Averaged data for two different frequencies are shown in Figure 3 (Fig. $3 A, C, 10 \mathrm{~Hz}, B, D, 50 \mathrm{~Hz}$ ). The mean EPSC amplitude is plotted for each stimulus in the train under control conditions and in the presence of $4 \mathrm{~mm} \gamma$-DGG (Fig. $3 A, B$ ). The data are normalized to the amplitude of the first EPSC in the train and plotted below (Fig. 3C,D). No difference is observed in the normalized curves during $10 \mathrm{~Hz}$ trains $(p>0.05 ; n=4)$, indicating that at low frequencies, short-term depression is caused wholly by presynaptic mechanisms rather than postsynaptic receptor desensitization. At higher frequencies the normalized EPSC amplitude in the presence of $\gamma$-DGG was potentiated (Fig. 3D, Table 1). These data suggest that $\gamma$-DGG acts to reduce desensitization by virtue of its effect as a competitive antagonist.

There are three observations that support the hypothesis that $\gamma$-DGG is acting to reduce desensitization of AMPA receptors. (1) The effect of $\gamma$-DGG is frequency dependent: at low frequencies (10 Hz and below) the short-term depression time course is unaffected by $\gamma$-DGG (Fig. 3C), whereas higher frequencies exhibit proportionally greater levels of potentiation by $\gamma$-DGG (Table 1). This suggests that the $\gamma$-DGG action is not caused by nonspecific effects at other modulatory sites, because such effects should be independent of stimulus frequency. (2) KYN, another competitive antagonist that also has fast kinetics, produced ef- fects similar to $\gamma$-DGG (see Fig. 10A). (3) These observations can be reproduced by competitive antagonism of AMPA receptors in a computational model of the calyx of Held.

\section{Modeling of transmitter release and desensitization}

To interpret the experimental results, we have developed a computational model of synaptic transmission at the calyx of Held (Graham et al., 2001). The model parameters are given in Materials and Methods, and the state diagram is shown in Figure $4 A$. There are three closed states, three blocked states, two open states, and two desensitized states, and antagonist competes with agonist for two binding sites. The model proposed in Figure 4 is an amalgamation of models describing the kinetics of $\gamma$-DGG binding to AMPA receptors in the cerebellum (Diamond and Jahr, 1997; Wadiche and Jahr, 2001) and the Raman and Trussell $(1992,1995)$ model of AMPA
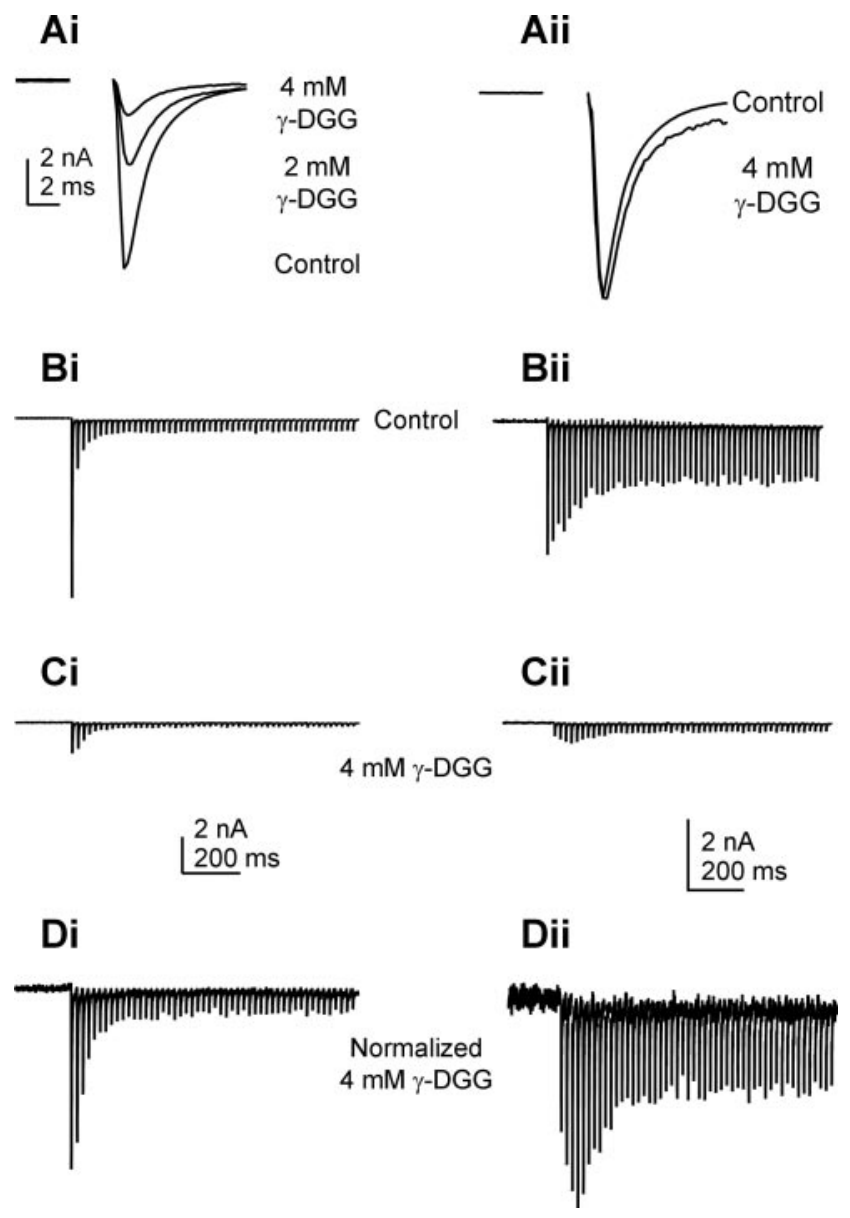

Figure 2. $\quad \gamma$-DGG reduces the EPSC amplitude, unmasks facilitation, and reduces short-term depression. Ai, Effect of $\gamma$-DGG on the amplitude of a single EPSC. Traces are mean of 20 EPSCS in the absence (control) and presence of either 2 or $4 \mathrm{~mm} \gamma$-DGG. Aii, EPSC amplitudes in the presence of $\gamma$-DGG normalized to the peak EPSC in control conditions. $B-D$, Effect of $\gamma$-DGG on the EPSC amplitude during a $50 \mathrm{~Hz}$ train. Control $(B), \gamma$-DGG $(C)$, and normalized data $(D)$ from two different neurons are shown in $i$ and ii. Bi, Control. After an initial large EPSC, there is rapid depression to a low steady-state level ( $<10 \%$ of initial EPSC amplitude), which is maintained throughout the train. Bii, Control. In this neuron, the EPSC declines slowly, and the relative steady-state amplitude is greater than that for $i$, being $50 \%$ of initial EPSC amplitude. C, Bath application of $4 \mathrm{~mm} \gamma$-DGG reduces EPSC amplitude by $85 \%$ in both neurons (Ci, Cii). Di, The trace shown in $C i$ is scaled to the amplitude of the first EPSC in the control train (Bi). The amplitude of the steady-state EPSCs is higher with respect to the first EPSC. ii, The trace shown in Cii is scaled to the amplitude of the first EPSC in the control train (Bii). The EPSC now facilitates from the second to the eighth stimulus and then depresses, but to a higher steady-state amplitude relative to control. 
A

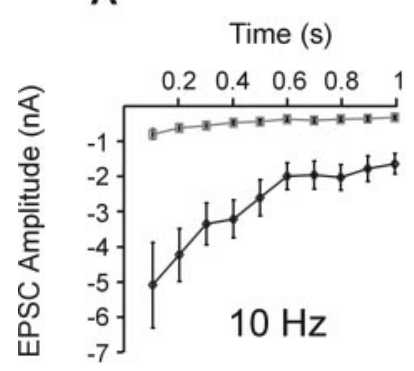

C

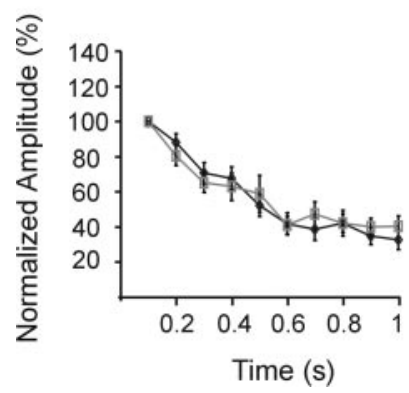

B

Time (s)

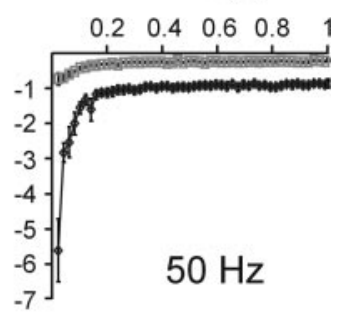

D

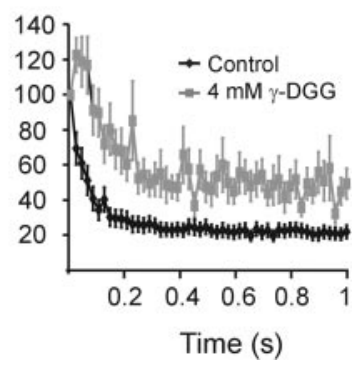

Figure 3. $\quad \gamma$-DGG had no effect on short-term depression during $10 \mathrm{~Hz}$ trains but has a marked effect during $50 \mathrm{~Hz}$ trains. Average EPSC amplitudes during the train are shown for four cells with EPSC trains at a frequency of 10 and $50 \mathrm{~Hz}$, under control conditions (black diamonds) and in the presence of $4 \mathrm{~mm} \gamma$-DGG (gray squares). A, Average EPSC amplitude during a $10 \mathrm{~Hz}$ train. B, Average EPSC amplitude during a $50 \mathrm{~Hz}$ train. C, Normalized EPSC amplitude during a 10 $\mathrm{Hz}$ train. Data with and without $\gamma-\mathrm{DGG}$ are superimposed and show a $60 \%$ depression at $1 \mathrm{sec}$. $D$, Normalized EPSC amplitude during a $50 \mathrm{~Hz}$ train. At this frequency, $\gamma$-DGG unmasks facilitation and reduces depression from 78 to $50 \%$ at $1 \mathrm{sec}$.

receptor kinetics at the avian nucleus magnocellularis. Neither model could account for our control EPSC trains and were adapted as follows. In the Wadiche and Jahr (2001) model the receptors tended to accumulate in a blocked state, leading to very small EPSCs even during low-frequency trains. Our model resolves this problem by accelerating the recovery from this blocked state (Fig. 4A, B1). The $\gamma$-DGG rate constants were then adjusted to match the doseresponse relationship found experimentally. Glutamate unbinding rates were also set to be of a similar order of magnitude $\left(R_{\mathrm{u}}{ }^{1}=\right.$ $6 / \mathrm{msec}, R_{\mathrm{u}}{ }^{2}=12 / \mathrm{msec}$ ) (Diamond and Jahr, 1997), and the desensitization rate constants were adjusted to give significant desensitization during a train at $50 \mathrm{~Hz}$ and little desensitization at $10 \mathrm{~Hz}$.

Short-term depression curves were modeled for both 10 and $50 \mathrm{~Hz}$ stimulus frequencies and are presented in a similar format to the synaptic data (Fig. $4 B-E$ ). The model was run under control conditions (in which glutamate receptors activate and could proceed into desensitized states) and then repeated in the "presence" of $4 \mathrm{~mm} \gamma$-DGG. At $10 \mathrm{~Hz}$ the EPSC train depressed to $\sim 40 \%$ of control amplitudes (Fig. $4 B$ ), and $\gamma$-DGG had little influence on the rate of depression (Fig. $4 D$ ). Model parameters were unchanged at $50 \mathrm{~Hz}$, although the vesicle recycling rate had to be increased from $1.8 / \mathrm{sec}$ at $10 \mathrm{~Hz}$ to $17 / \mathrm{sec}$ at $50 \mathrm{~Hz}$ to match the steady-state EPSC amplitudes seen experimentally and is compatible with an activity-dependent increase in vesicle recycling. Now the response depressed to $\sim 28 \%$ of control amplitudes (Fig. 4C), and $\gamma$-DGG block of the AMPA receptors unmasked an initial facilitation and reduced the rate and extent of short-term depression. Removal of desensitization from the model by making $R^{1}{ }_{\mathrm{d}}$ and $R^{2}{ }_{\mathrm{d}}=0$ mimicked the effect of $4 \mathrm{~mm}$

A

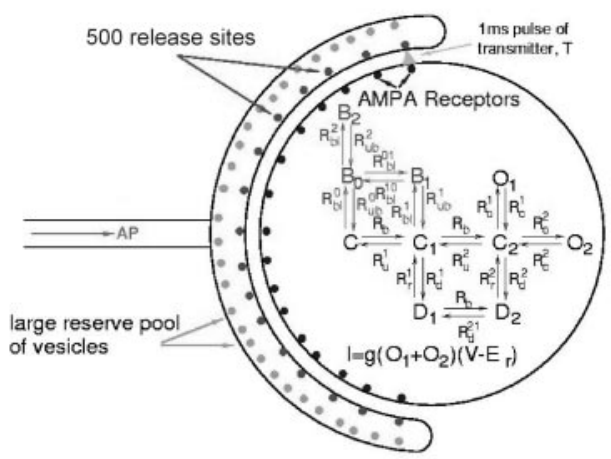

B

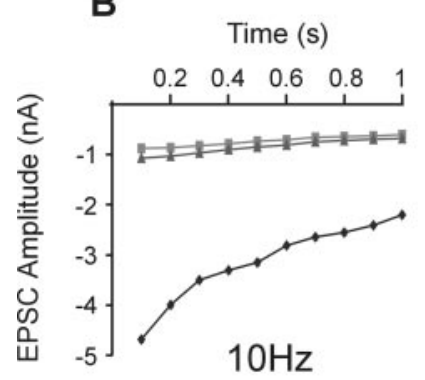

D

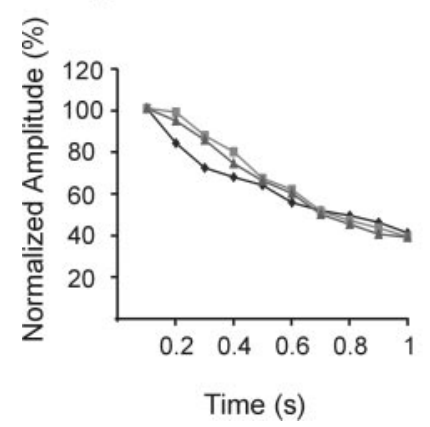

C

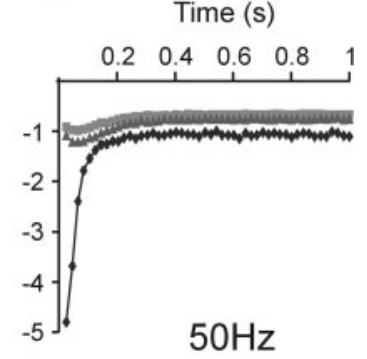

Figure 4. A computational model of transmission accounts for the frequency-dependent effect of $\gamma$-DGG by a simple competitive antagonist mechanism. $A$, The model of synaptic transmission at the calyx of Held: 500 active zones with initially five vesicles per active zone. Release probability is 0.17 per vesicle. See Materials and Methods for rate constants. $B-E$, Simulated EPSC short-term depression. Data are expressed as a mean \pm SEM of 10 individual runs in a manner similar to the experimental data shown in Figure 3. Black traces are in control conditions; light gray traces are in the presence of $4 \mathrm{~mm} \gamma$-DGG. Dark gray traces are with AMPA receptor desensitization disabled $\left(R_{\mathrm{d}}{ }^{1}\right.$ and $R_{\mathrm{d}}{ }^{2}$ set to 0$)$ in the presence of $4 \mathrm{~mm} \gamma$-DGG. $B$ and $C$ are simulated EPSC amplitudes for trains at frequencies of 10 and $50 \mathrm{~Hz}$. $D$ and $E$ are normalized EPSC amplitudes for trains at 10 and $50 \mathrm{~Hz}$, respectively.

$\gamma$-DGG (Fig. 4E). These data clearly demonstrate that we can explain the enhanced short-term depression at frequencies above $10 \mathrm{~Hz}$ purely in terms of relief from desensitization by the action of a competitive antagonist with rapid kinetics.

\section{The kinetics of the antagonist is critical for block} of desensitization

To demonstrate that the kinetics of the antagonist is crucial in blocking desensitization, the effect of changing the antagonist blocking rates was modeled for rate constants between 0.000006 $\mathrm{mM}-\mathrm{msec}^{-1}$ to $60,000 \mathrm{mM}-\mathrm{msec}^{-1}$ and plotted against the percentage depression during a $50 \mathrm{~Hz}$ train (Fig. $5 A$ ). The ratio of 
A

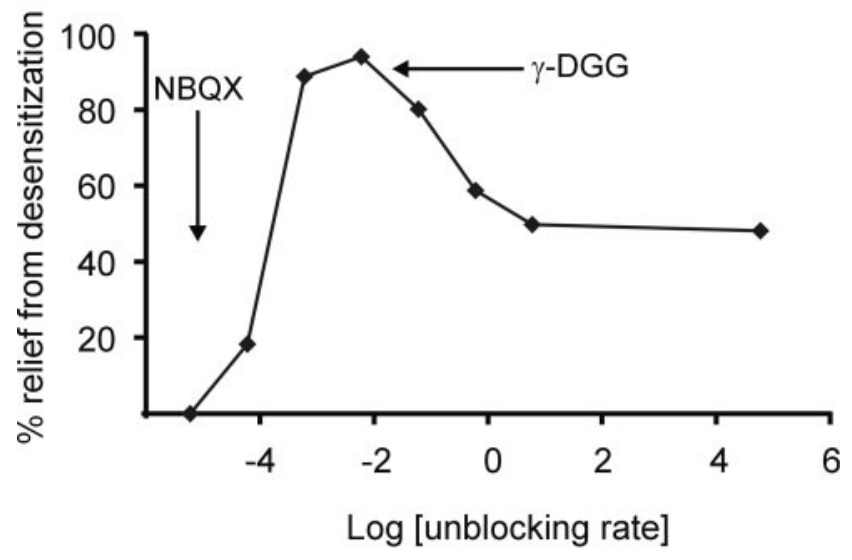

B

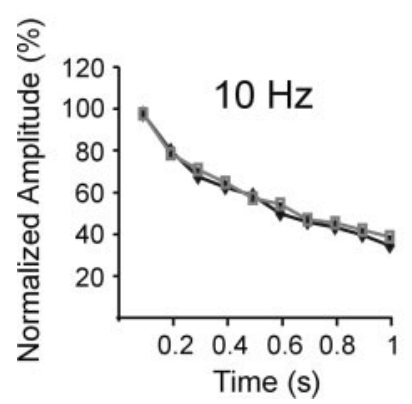

C

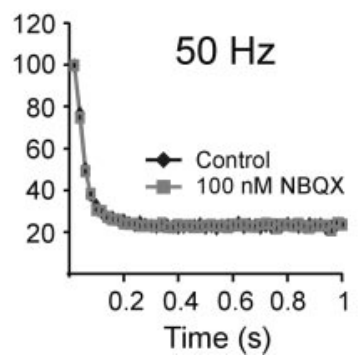

Figure 5. Competitive antagonists with slow kinetics do not suppress desensitization. $A$, Changing the kinetics of the competitive antagonist has a marked effect on the efficacy of relief from desensitization. The unblocking rate constant is plotted against the amount of relief from desensitization. Unblocking rates of an antagonist were changed from $0.000006 \mathrm{~mm}-\mathrm{msec}^{-1}$ to $60,000 \mathrm{~mm}-\mathrm{msec}^{-1}$ for a mechanism with a single blocked state. The ratio of blocking and unblocking rates was kept constant $\left(R_{\mathrm{bl}} / R_{\mathrm{ub}}=11.67 \mathrm{~mm}\right)$. Data are mean $\pm \mathrm{SEM}$ of 10 runs at $50 \mathrm{~Hz}$ at each unblocking rate. The bell-shaped distribution shows that there is an optimum rate that provides maximal relief from desensitization. $\gamma$-DGG has rate constants that provide $93 \%$ relief of desensitization. In contrast, NBQX has kinetics that provides no relief (arrows). $B, C$, Antagonists with slow kinetics fail to protect from desensitization in the model. Normalized data in the presence (gray squares) and absence (black diamonds) of 100 nM NBQX. Average data are shown as mean \pm SEM of 10 separate runs for 10 and $50 \mathrm{~Hz}$ trains.

blocking and unblocking rates was kept constant $\left(R_{\mathrm{bl}} / R_{\mathrm{ub}}=\right.$ $11.67 \mathrm{~mm}$ ). The bell-shaped distribution suggests that a competitive antagonist must have an optimum rate to provide maximum relief from desensitization. A similar distribution was observed when blocking rates were changed between $0.00007{\mathrm{mM}-\mathrm{msec}^{-1}}^{-1}$ and 700,000 mM- $\mathrm{msec}^{-1}$. Too slow a rate and receptors are sequestered into a blocked state from which there is little or no re-equilibration during the interstimulus interval. If the blocking/unblocking rate is too fast, there will be re-equilibration within each EPSC because the agonist too quickly displaces the antagonist. $\gamma$-DGG (4 mM) decreases the amount of desensitization during a train of EPSCs at $50 \mathrm{~Hz}$ by $93 \%$, suggesting that the kinetics of this antagonist is very close to optimal. On the other hand, a low concentration (100 nM) of the slowly equilibrating competitive antagonist NBQX should provide no protection from desensitization because of its slow kinetics. This is shown for stimulus frequencies of 10 and $50 \mathrm{~Hz}$ (Fig. $5 \mathrm{~B}, \mathrm{C}$ ). AMPA receptor parameters were unchanged from Figure 4, but to reflect the kinetics of NBQX block, the rate constants for NBQX binding $\left(R_{\mathrm{bl}}\right)$ and unbinding $\left(R_{\mathrm{ub}}\right)$ were $0.28 / \mathrm{mM}-\mathrm{msec}$ and $0.0000033 /$

A
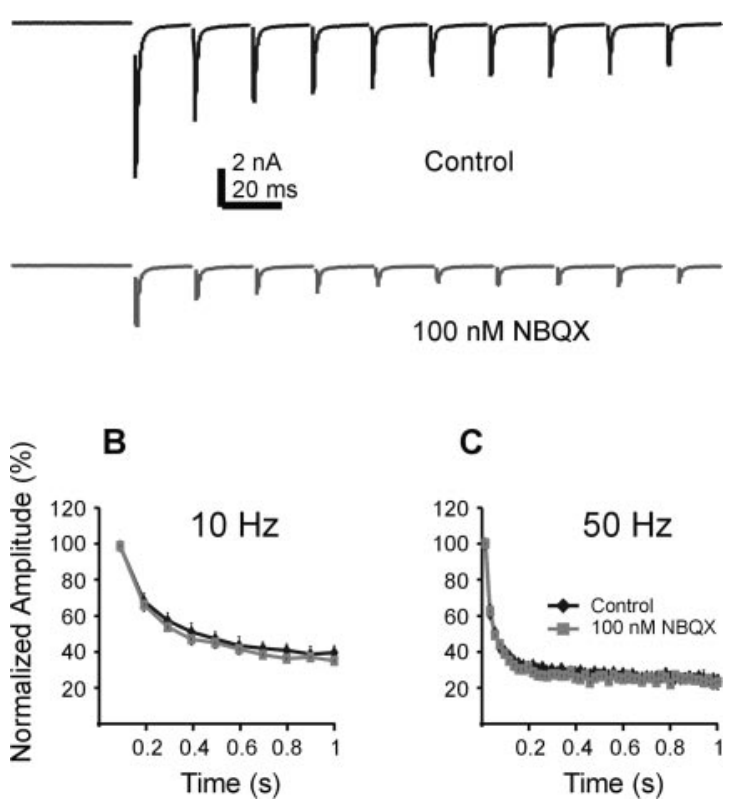

Figure 6. Experimentally, NBQX reduces EPSC amplitude but has no effect on the rate of short-term depression. A, Raw data: Top trace, control; bottom trace, $100 \mathrm{~nm} \mathrm{NBQX}$. The first 200 msec of a $50 \mathrm{~Hz}$ train of 1 sec duration is shown. NBQX blocks EPSC amplitude by $60 \%$. B, C, Normalized EPSC amplitudes ( $n=4$ ) in the presence (gray squares) and absence (black diamonds) of $100 \mathrm{~nm} \mathrm{NBQX.} \mathrm{Average} \mathrm{data} \mathrm{are} \mathrm{mean} \pm$ SEM for four cells in both conditions. Both $\gamma$-DGG and NBQX reduce EPSC amplitude, but in contrast to $\gamma$-DGG, NBQX has no effect on short-term depression during low- or high-frequency trains.

msec, respectively (cf. $R_{\mathrm{bl}}{ }^{0}=70 / \mathrm{mM}-\mathrm{msec}$ and $R_{\mathrm{ub}}{ }^{0}=6 / \mathrm{msec}$ for $\gamma$-DGG). Adding this blocked state to the model decreased the initial EPSC of the train from $4.8 \pm 0.05$ to $0.5 \pm 0.06 \mathrm{nA}$ at $10 \mathrm{~Hz}$ and $4.5 \pm 0.05$ to $0.49 \pm 0.06 \mathrm{nA}(n=10 \mathrm{runs})$ at $50 \mathrm{~Hz}$. However, after normalization, application of NBQX did not change the rate or magnitude of depression during a simulated $1 \mathrm{sec}$ train at 10 or $50 \mathrm{~Hz}$ (Fig. $5 \mathrm{~B}, C)(n=10)$, suggesting that the only effect of NBQX is to sequester a proportion of receptors into a longlived blocked state where there is little or no re-equilibration of blocked and unblocked receptors between EPSCs.

Identical results were obtained on application of $100 \mathrm{~nm}$ NBQX to the calyx synapse. Average data at each frequency (10 and $50 \mathrm{~Hz}$ ) are shown in the presence and absence of NBQX. The data were then normalized to the amplitude of the initial EPSC and plotted in Figure 6, $B$ and $C$. Initial EPSC amplitudes were reduced by $60 \%$ in the presence of NBQX (Fig. $6 \mathrm{~A}$ ) in all four cells tested ( $5.9 \pm 0.78$ to $2.4 \pm 0.26 \mathrm{nA}$; pooled data not shown). However, there is no difference in the depression curves at either stimulus frequency (Fig. $6 B, C)(p>0.05 ; n=4)$, implying that application of NBQX does not affect the kinetics of synaptic depression during low- and high-frequency trains. In addition, there is no difference in the magnitude of depression between the modeled data and the experimental data at both stimulus frequencies. The model predicts $70 \%$ depression during a $50 \mathrm{~Hz}$ train (Fig. $5 C$ ) in the presence or absence of NBQX, which is borne out by the experimental data (Fig. 6C), which shows that the steady-state EPSC amplitude is 30\% of the initial EPSC amplitude in the presence and absence of NBQX.

Thus, the slow kinetics of the competitive antagonist NBQX reduces the total number of receptors able to sense glutamate, without allowing re-equilibration during the interstimulus interval. 
A
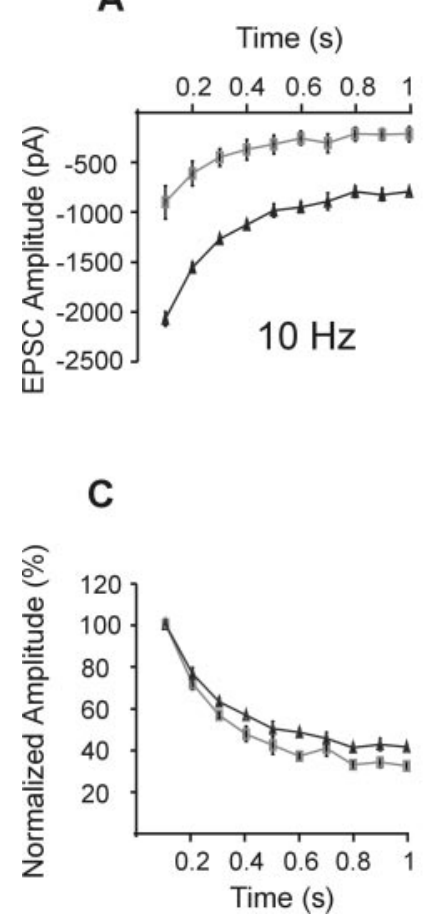

B

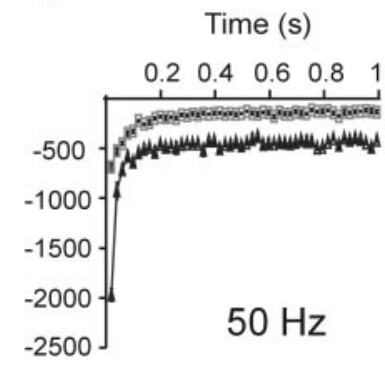

D

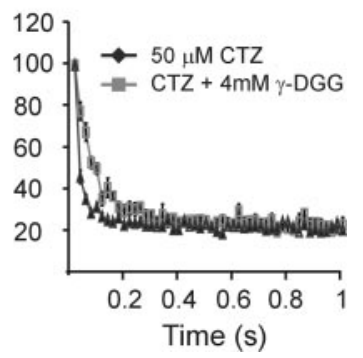

Figure 7. Use of $\mathrm{CTZ}$ and $\gamma$-DGG together provide no relief from desensitization. Average data are shown for four cells in the same format as Figure 3 with EPSC trains at 10 and $50 \mathrm{~Hz}$ in the presence of $50 \mu \mathrm{M}(\mathrm{CZ}$, before (black diamonds) and during (gray squares) application of 4 mm $\gamma$-DGG. A, Average data for a $10 \mathrm{~Hz}$ train. B, Average data for a $50 \mathrm{~Hz}$ train. C, Normalized data for the $10 \mathrm{~Hz}$ train. D, Normalized data during the $50 \mathrm{~Hz}$ train. In the presence of CTZ, $\gamma$-DGG has no effect on the steady-state EPSC amplitude measured at the end of a 1 sec train.

\section{Do the effects of CTZ and $\gamma$-DGG summate}

Because KYN and $\gamma$-DGG have been used previously to reduce saturation and used in combination with CTZ (Neher and Sakaba, 2001a,b; Taschenberger et al., 2002), we wondered whether the effects of $\gamma$-DGG and CTZ on EPSC desensitization would be complementary. We repeated the experiments shown in Figure 3 in the presence of both $50 \mu \mathrm{M} \mathrm{CTZ}$ and $4 \mathrm{~mm} \gamma$-DGG. The results (Fig. 7C,D) from four separate cells showed no change in short-term depression parameters from control data collected in the absence of both drugs at both stimulus frequencies; hence the mechanisms are not complementary and probably incompatible. A possible explanation is that CTZ may stabilize a long-lived closed state into which receptors accumulate during repetitive stimulation, with a conformation similar to that seen by Sun et al., (2002). The precise mechanism is not germane to the current work, except insofar as it suggests that combined application of KYN or $\gamma$-DGG with CTZ provides little additional protection from that afforded by CTZ alone.

Estimation of the effective concentration required to block desensitization was made empirically by plotting the relief from short-term depression against the percentage block of the initial EPSC for data using $\gamma$-DGG concentrations between 2 and $4 \mathrm{~mm}$ and is shown in Figure 8. The solid curve shows the predicted block of desensitization by changing $\gamma$-DGG concentrations in the AMPA receptor model. Although there is a large scatter, we can conclude that more than half of the AMPA receptors must be blocked to detect relief from desensitization and that optimum relief is approached at $\sim 80 \%$ AMPA receptor block.

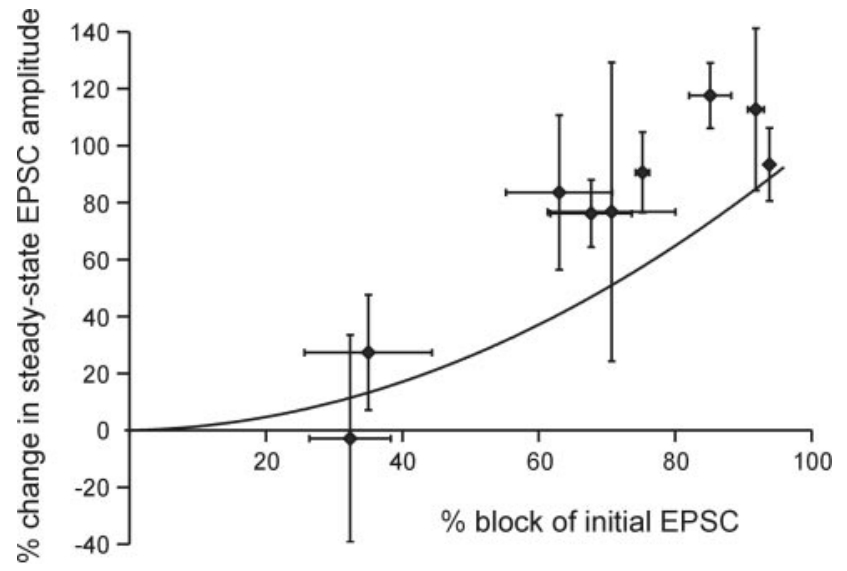

Figure 8. Magnitude of EPSC block by $\gamma$-DGG correlates with block of desensitization. The change in the steady-state EPSC amplitudes on application of $\gamma$-DGG (an index to the extent of desensitization) is plotted against the percentage block of the initial EPSC by $\gamma$-DGG. Data are plotted as one cell per data point using a stimulus frequency of $50 \mathrm{~Hz}$. Line is a polynomial fit to data $\left(r^{2}=0.99\right)$ modeled at different concentrations of $\gamma$-DGG producing between 20 and $90 \%$ block of initial EPSC amplitude ( 0.25 and 4 mm $\gamma$-DGG).

\section{Estimation of the readily releasable pool}

Our results have several important implications for the interpretation of data from studies using repetitive stimulation. For instance, cumulative EPSC amplitude plots that give an estimation of the readily releasable pool (and rates of vesicle recycling) are likely to have been underestimated because of desensitization. The $y$-axis intercept, obtained by extrapolation of the linear regression line through the steady-state portion of the train, is an indication of the readily releasable pool size. This value is significantly different in control and in the same cells after $\gamma$-DGG application (13 $\pm 1.3 \mathrm{nA}$ in control and $22 \pm 3.2 \mathrm{nA}$ in $\gamma$-DGG; $p>0.05 ; n=4)$. Assuming an average miniature EPSC amplitude of $28.7 \mathrm{pA}$ (Schneggenburger et al., 1999), which equates to an average mEPSC conductance of $35 \mathrm{pS}$, our estimate of the readily releasable pool in control conditions is $645 \pm 63$ vesicles ( $n=4$ cells). In the presence of $4 \mathrm{~mm} \gamma$-DGG, this increases to $1069 \pm 152$ vesicles $(n=4)$. This suggests that under control conditions, the pool size has been significantly underestimated $(p<0.05)$ by approximately half because of desensitization (Fig. 9).

\section{Temperature}

To allow comparison with in vivo data, we have reexamined the impact of desensitization on trains of EPSCs at a physiological temperature of $37^{\circ} \mathrm{C}$. The data shown in Figure 10 indicate that the processes of facilitation and depression are qualitatively similar to experiments at $26^{\circ} \mathrm{C}$. The magnitude of facilitation at $37^{\circ} \mathrm{C}$ was reduced, whereas the contribution of desensitization was similar to that at lower temperatures. It seems likely that the reduced facilitation reflects shorter presynaptic action potential duration and hence a lower calcium influx at physiological temperatures.

\section{Kynurenic acid has a similar effect to $\gamma$-DGG}

At $37^{\circ} \mathrm{C}, 200 \mathrm{~Hz}$ trains were delivered in the absence and presence of $2 \mathrm{~mm} \mathrm{KYN} \mathrm{(Fig.} \mathrm{10A)} \mathrm{and} \mathrm{the} \mathrm{amount} \mathrm{of} \mathrm{depression} \mathrm{was}$ compared with similar trains delivered in the presence of $4 \mathrm{~mm}$ $\gamma$-DGG (Fig. 10B). Average EPSC amplitude in control conditions was $6.1 \pm 0.37 \mathrm{nA}$, which was reduced to $0.85 \pm 0.1 \mathrm{nA}$ after KYN application. Both antagonists gave a similar reduction in EPSC amplitude (Fig. 10C) $(84 \pm 0.7 \%$ for $\gamma$-DGG; $86 \pm 2.3 \%$ for $\mathrm{KYN}$ ), suggesting that DGG is a lower affinity antagonist. Both KYN and $\gamma$-DGG increased the amplitude of the steady- 

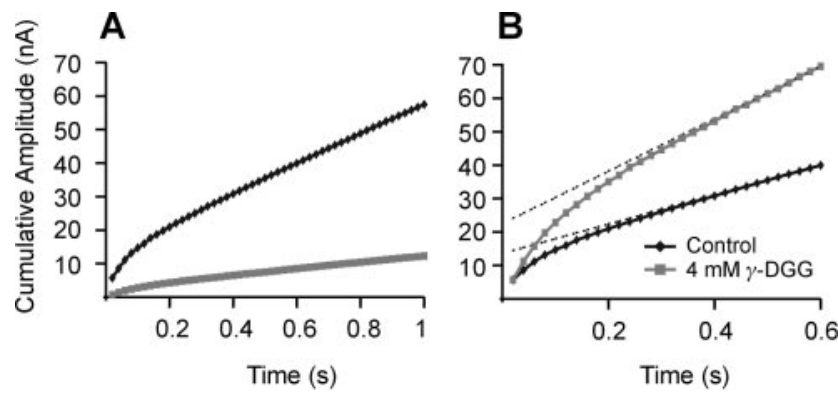

Figure 9. Estimation of the readily releasable pool size from cumulative EPSC amplitude after block of desensitization. Data are mean of four cells with EPSC trains at a frequency of 50 $\mathrm{Hz}$, under control conditions (black diamonds) and in the presence (gray squares) of $4 \mathrm{~mm}$ $\gamma$-DGG. $A, \gamma$-DGG reduces EPSC amplitude and hence the cumulative EPSC amplitude during a $50 \mathrm{~Hz}$ train. $B$, Scaling the $\gamma$-DGG trace relative to the amplitude of the initial EPSC corrects for the EPSC block, permitting estimation of the readily releasable pool size in the absence of desensitization. Linear regression fits were constructed by fitting a straight line through the data points obtained during the last half of the train $(0.5-1 \mathrm{sec})$ in both cases. The $y$-axis intercept of the regression line gives the estimate of the pool size, suggesting that under contro conditions, the pool size has been underestimated by approximately half. $\gamma$-DGG also increased the gradient of the regression line, from $44 \pm 5$ to $79 \pm 4.5 \mathrm{nA} / \mathrm{sec}$.

A

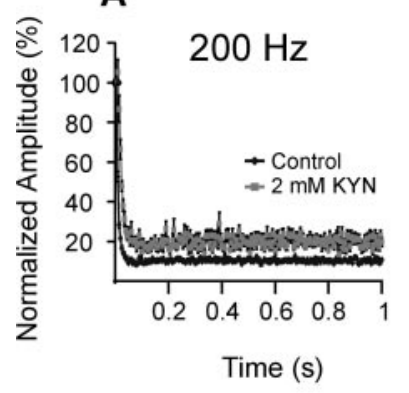

C
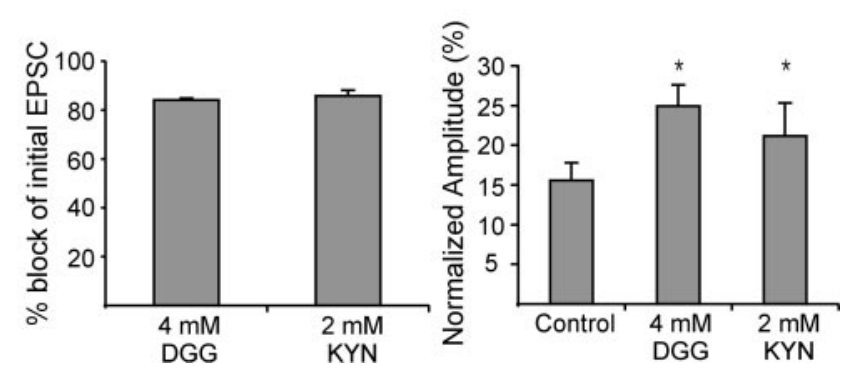

Figure 10. Kynurenate and $\gamma$-DGG block desensitization at physiological temperature and stimulus frequency $\left(37^{\circ} \mathrm{C} ; 200 \mathrm{~Hz}\right.$ train). Average data are shown for four cells, under control conditions (black diamonds) and in the presence of either $4 \mathrm{~mm} \gamma$-DGG or 2 mм KYN (gray squares). $A$, Normalized data for control EPSC trains and trains in the presence of KYN. $B$, Normalized data for control trains and with $\gamma$-DGG. C, Bar graph showing that $\gamma$-DGG and KYN block initial EPSC amplitude to the same extent. $D, K Y N$ and $\gamma$-DGG decrease the amount of depression observed during a train. The graph shows the amplitude of the final EPSC expressed relative to the amplitude of the initial EPSC of the train. Asterisks indicate statistical significance (Student's t test; $p<0.05$ ).

state EPSC at the end of a train relative to the initial EPSC. Application of $2 \mathrm{~mm}$ KYN led to a significant increase of steady-state amplitude from $16 \pm 0.4$ to $21 \pm 0.4 \%(p<0.05 ; n=6)$, whereas application of $4 \mathrm{~mm} \gamma$-DGG increased steady-state EPSC amplitude from $15 \pm 0.3$ to $25 \pm 0.3 \%$ of control (Fig. $10 D)(p<0.05$; $n=6)$. These data suggest that both KYN and $\gamma$-DGG can effectively reduce postsynaptic AMPA receptor desensitization and suggest that $\gamma$-DGG provides more protection from desensitiza- tion than KYN, possibly because $\gamma$-DGG has a faster off-rate because of its low affinity.

\section{Discussion}

We have shown that AMPA receptor desensitization plays a significant role in synaptic depression during repetitive synaptic transmission. Our method, using low-affinity competitive antagonists with fast off-rates, diverts receptor kinetics away from desensitization and allows re-equilibration of the blocked and unblocked receptors within the interstimulus interval. Modeling the AMPA receptor kinetics and transmitter release at the calyx of Held demonstrated that this process could account for the experimental observations. The results are consistent with desensitization playing a minimal role in synaptic depression at low frequencies $(<10 \mathrm{~Hz})$ but clearly indicate that desensitization plays an increasing role at higher frequencies and that desensitization is an integral component of short-term depression at functional synapses after hearing onset.

\section{AMPA receptor desensitization}

The extent to which postsynaptic receptor desensitization contributes to depression of EPSCs is an important question (Trussell et al., 1988, 1993; Otis et al., 1996) and of particular relevance during high-frequency trains, in which the desensitization recovery time course is longer than the interstimulus interval. Desensitization can be blocked using drugs such as aniracetam and cyclothiazide (Bertolino et al., 1993; Partin et al., 1993; Trussell et al., 1993), but the efficacy of block at AMPA receptors containing the flop cassette (Partin et al., 1994) is much lower than the "flip" spliced variants. Kinetic studies suggest that cyclothiazide reduces the rate of entry into desensitized states (Partin et al., 1996) by stabilization of a closed nondesensitized state, and this has been shown recently to have a structural meaning through destabilization of S1/S2 dimers (Robert et al., 2001; Sun et al., 2002). The link between CTZ efficacy and the presence of the flip cassette also implies that native synapses expressing differing combinations of flip-flop splice variants are not uniformly sensitive to this drug. In addition, CTZ has nonspecific presynaptic effects on synaptic transmission (Barnes-Davies and Forsythe, 1995; Diamond and Jahr, 1995; Bellingham and Walmsley, 1999) that are mediated through inhibition of presynaptic potassium and calcium currents and potentiation of spontaneous mEPSC frequency (Ishikawa and Takahashi, 2001). Examination of EPSC variance versus mean amplitude at the calyx of Held also suggests that desensitization plays a role in short-term synaptic depression and that CTZ cannot fully protect AMPA receptors from desensitization during physiological trains of stimuli (Meyer et al., 2001; Scheuss et al., 2002). Application of CTZ can also generate apparent facilitation during an EPSC train by slowing the decay time of each individual EPSC (Meyer et al., 2001; Scheuss et al., 2002), thus increasing temporal summation and complicating the analysis, because some AMPA receptors are not deactivating during the interstimulus interval. These effects, along with the fact that $\mathrm{CTZ}$ alters receptor kinetics and provides incomplete relief from desensitization, make it difficult to interpret physiological experiments in the presence of CTZ.

In the auditory pathway, the time course of AMPA receptormediated EPSCs is very fast (Raman et al., 1994; Barnes-Davies and Forsythe, 1995; Isaacson and Walmsley, 1996). The auditory brainstem is known to express high levels of flop subunits and to express a higher proportion of the calcium-permeable GluR4 as opposed to GluR2 subunits (Geiger et al., 1995; Otis et al., 1995; Ravindranathan et al., 2000). These subunits show rapid deactivation and desensitization (Mosbacher et al., 1994) and can dom- 
inate heteromeric channel kinetics. Recovery from desensitization is also fast in auditory pathways expressing GluR $4_{\text {flop }}$ (e.g., $\tau_{\mathrm{r}}$ $16 \mathrm{msec}$ ) (Raman and Trussell, 1995) but can be much slower (e.g., $\tau_{\mathrm{r}} 450 \mathrm{msec}$ in hippocampal granule cells) (Colquhoun et al., 1992). Slow recovery times favor accumulation of receptors in desensitized states, particularly as stimulus frequency increases.

\section{Mechanism of protection by competitive antagonists}

Our approach avoids these difficulties by using low-affinity antagonists possessing fast off-rates to divert receptor kinetics away from desensitization. Competition between agonists and low-affinity competitive antagonists has been used previously at NMDA receptors to estimate the peak concentration and clearance rates of glutamate from the synaptic cleft (Clements et al., 1992). In the present experiments the aim was to sequester the majority of the receptors into a blocked pool, so that the number of receptors available to sense glutamate from the first EPSC is reduced. After each subsequent EPSC in the stimulus train, re-equilibration of the blocked and unblocked receptor pools means that each EPSC is detected by a different subset of receptors. Any receptors that bind glutamate and proceed to desensitization have an extended interval (between 5 and 10 times as long, on average) in which to recover from desensitization before their next exposure to neurotransmitter. Both KYN and $\gamma$-DGG are competitive antagonists at AMPA receptors (Diamond and Jahr, 1997; Wadiche and Jahr, 2001), and KYN (1-2 mM) (Neher and Sakaba, 2001a) has been used to minimize AMPA receptor saturation during maximal release protocols at the calyx. We and others (Schneggenburger et al., 1999; Ishikawa et al., 2002) have confirmed that transmission is not saturated at the calyx of Held, because EPSC amplitude increases with raised extracellular calcium. Our experiments were conducted using 2-4 mM $\gamma$-DGG, blocking between 30 and $90 \%$ of the subsynaptic AMPA receptors, or $2 \mathrm{~mm}$ KYN, blocking $86 \%$ of receptors. An obvious limiting factor in using this method of protection from desensitization is that the antagonist reduces EPSC amplitude to one-fifth of control levels; however, averaging of the response train provides a straightforward means of maintaining the signal-to-noise ratio when EPSC amplitudes are small. Presynaptic actions of $\gamma$-DGG have been excluded at the climbing fiber synapse (Wadiche and Jahr, 2001). Furthermore, the frequency-dependent block of desensitization (having no effect at low stimulus frequencies, e.g., $10 \mathrm{~Hz}$ ) and the similar effect by two different antagonists with fast kinetics ( $\gamma$-DGG and KYN) combined with the modeling results support the hypothesis that these drugs are acting specifically as competitive antagonists at AMPA receptors. However, this method requires brief repetitive stimulation with intervening "rest" periods to enable receptor-antagonist reequilibration. This technique would be inappropriate when attempting to minimize desensitization during long $(>5 \mathrm{msec})$ agonist applications; rather CTZ may prove more effective in reducing desensitization under these circumstances (Neher and Sakaba, 2001b).

A surprising empirical observation was that the fast competitive antagonists were ineffective at blocking desensitization in the presence of CTZ. This could be attributable to CTZ stabilizing a minor but long-lived inactive state, into which receptors accumulate during repetitive stimulation, perhaps equivalent to that described crystallographically by Sun et al., (2002). Several reports have suggested that desensitization (Wang and Kaczmarek, 1998; Taschenberger et al., 2002) plays a minor role in short-term depression at the calyx of Held. Our results clearly contradict these data and indicate that desensitization plays an important role. Our studies of CTZ show that when used alone it is not effective as a blocker of desensitization during action potential stimulation at the calyx in animals aged $10 \mathrm{~d}$ and older. Interactions between low-affinity antagonists and CTZ are less effective than using low-affinity antagonists alone (Fig. 7). Our results suggest that previous estimates of quantal content using physiological trains of action potentials have underestimated pool size (Schneggenburger et al., 1999) because of the accumulation of desensitization. Our readily releasable pool size estimate of $>1000$ vesicles closely equates with the number of vesicles docked within 10 nm of active zones (Sätzler et al., 2002) and is similar to estimates of pool size obtained by Meyer et al. (2001) and Sheuss et al. (2002).

\section{Synaptic transmission and AMPA receptor model}

One of the strengths of this model is that it can account for shortterm depression over a range of frequencies. In refining the parameters, several additional implications for the physiology of transmission at the calyx of Held are apparent. For instance, only models incorporating a frequency-dependent increase in the rate of vesicle replenishment at active zones could give adequate fits to our data. Models incorporating fixed vesicle recycling rates (i.e., without activity-dependent refilling) were unable to match the time course and extent of depression over a range of frequencies, except when desensitization made little or no contribution to short-term depression. Another surprising result from the model was that the masking of facilitation at $50 \mathrm{~Hz}$ stimulation was caused entirely by the rapid onset of desensitization, i.e., postsynaptic rather than presynaptic effects. This was achieved by each active zone containing multiple docked vesicles before the onset of stimulation and is consistent with physiological studies suggesting multiple docked vesicles at each release site (Meyer et al., 2001; Sätzler et al., 2002; Taschenberger et al., 2002). Thus during the first few action potentials of a train, a relatively large number of consecutive releases occur from the same active zones, so that in subsequent stimuli their subsynaptic receptors were already desensitized. If active zones initially contained only one (or zero) releasable vesicle, then the onset of desensitization was too slow to mask facilitation. Consistent with our empirical experimental observations, the low release probability of each vesicle $(0.17)$ means that multivesicular release is rare. Although by no means definitive, these observations are of circumstantial significance in model refinement.

\section{Physiological relevance}

Correct assignment and definition of presynaptic and postsynaptic elements of short-term depression are an essential prerequisite for understanding synaptic physiology during trains of stimuli. Few studies have examined the role of desensitization during sustained repetitive synaptic stimulation. Substantial differences in the balance between facilitation and depression have a powerful impact on synaptic efficacy (Markram and Tsodyks, 1996; Thomson, 2000). Differences in desensitization contribute to these mechanisms across a range of glutamatergic synapses, for instance, at multipolar and bipolar cells in neocortex (Rozov et al., 2001). Our technique will allow the presynaptic mechanisms of vesicle recycling to be addressed using physiological stimuli and will be of broad application to many synapses using a range of AMPA receptor subunits. Although vesicle depletion is the dominant mechanism of short-term depression during trains of stimuli at the calyx of Held, we show that removing desensitization doubles steady-state EPSC amplitude relative to control conditions and that desensitization accounts for up to $40 \%$ of the total depression during the train.

\section{References}

Barnes-Davies M, Forsythe ID (1995) Pre- and postsynaptic glutamate receptors at a giant excitatory synapse in rat auditory brainstem slices. J Physiol (Lond) 488:387-406.

Bellingham MC, Walmsley B (1999) A novel presynaptic inhibitory mechanism underlies paired pulse depression at a fast central synapse. Neuron 23:159-170. 
Bertolino M, Baraldi M, Parenti C, Braghiroli D, DiBella M, Vicini S, Costa E (1993) Modulation of AMPA/kainate receptors by analogues of diazoxide and cyclothiazide in thin slices of rat hippocampus. Receptors Channels 1:267-278.

Billups B, Wong AYC, Forsythe ID (2002) Detecting synaptic connections in the medial nucleus of the trapezoid body using calcium imaging. Pflügers Arch 444:663-669.

Clements JD, Lester RA, Tong G, Jahr CE, Westbrook GL (1992) The time course of glutamate in the synaptic cleft. Science 258:1498-1501.

Colquhoun D, Jonas P, Sakmann B (1992) Action of brief pulses of glutamate on AMPA/kainate receptors in patches from different neurones of rat hippocampal slices. J Physiol (Lond) 458:261-287.

Diamond JS, Jahr CE (1995) Asynchronous release of synaptic vesicles determines the time course of the AMPA receptor-mediated EPSC. Neuron 15:1097-1107.

Diamond JS, Jahr CE (1997) Transporters buffer synaptically released glutamate on a submillisecond time scale. J Neurosci 17:4672-4687.

Edmonds B, Gibb AJ, Colquhoun D (1995) Mechanisms of activation of glutamate receptors and time course of excitatory synaptic currents. Annu Rev Physiol 57:495-519.

Forsythe ID, Westbrook GL (1988) Slow excitatory postsynaptic currents mediated by activation of $N$-methyl-D-aspartate receptors on cultured mouse central neurones. J Physiol (Lond) 396:515-534.

Fortune ES, Rose GJ (2001) Short-term synaptic plasticity as a temporal filter. Trends Neurosci 24:381-385.

Fuhrmann G, Segev I, Markram H, Tsodyks M (2002) Coding of temporal information by activity-dependent synapses. J Neurophysiol 87:140-148.

Geiger JRP, Melcher T, Koh DS, Sakmann B, Seeburg PH, Jonas P, Monyer H (1995) Relative abundance of subunit mRNAs determines gating and $\mathrm{Ca}^{2+}$ permeability of AMPA receptors in principal neurons and interneurones in rat CNS. Neuron 15:193-204.

Graham BP, Wong AYC, Forsythe ID (2001) A computational model of synaptic transmission at the calyx of Held. Neurocomputing 38-40:37-42.

Hines ML, Carnevale NT (1997) The NEURON simulation environment. Neural Comput 9:1179-1209.

Hjelmstad GO, Isaac JT, Nicoll RA, Malenka RC (1999) Lack of AMPA receptor desensitization during basal synaptic transmission in the hippocampal slice. J Neurophysiol 81:3096-3099.

Isaacson JS, Walmsley B (1996) Amplitude and time course of spontaneous and evoked excitatory postsynaptic currents in bushy cells of the anteroventral cochlear nucleus. J Neurophysiol 76:1566-1571.

Ishikawa T, Sahara Y, Takahashi T (2002) A single packet of transmitter does not saturate postsynaptic glutamate receptors. Neuron 34:613-621.

Iwasaki S, Takahashi T (2001) Developmental regulation of transmitter release at the calyx of Held in rat auditory brainstem. J Physiol (Lond) 534:861-871.

Jones MV, Westbrook GL (1996) The impact of receptor desensitization on fast synaptic transmission. Trends Neurosci 19:96-101.

Markram H, Tsodyks M (1996) Redistribution of synaptic efficacy between neocortical pyramidal neurons. Nature 382:807-810.

Mayer ML, Vyklicky L Jr (1989) Concanavalin A selectively reduces desensitization of mammalian neuronal quisqualate receptors. Proc Natl Acad Sci USA 86:1411-1415.

Meyer AC, Neher E, Schneggenburger R (2001) Estimation of quantal size and number of functional active zones at the calyx of Held synapse by nonstationary EPSC variance analysis. J Neurosci 21:7889-7900.

Mosbacher J, Schoepfer R, Monyer H, Burnashev N, Seeburg PH, Ruppersberg JP (1994) A molecular determinant for submillisecond desensitization in glutamate receptors. Science 266:1059-1062.

Neher E, Sakaba T (2001a) Combining deconvolution and noise analysis for the estimation of transmitter release rates at the calyx of Held. J Neurosci 21:444-461.

Neher E, Sakaba T (2001b) Estimating transmitter release rates from postsynaptic current fluctuations. J Neurosci 21:9638-9654.

Otis T, Zhang S, Trussell LO (1996) Direct measurement of AMPA receptor desensitization induced by glutamatergic synaptic transmission. J Neurosci 16:7496-7504.

Otis TS, Raman IM, Trussell LO (1995) AMPA receptors with high $\mathrm{Ca}^{2+}$ permeability mediate synaptic transmission in the avian auditory pathway. J Physiol (Lond) 482:309-315.

Partin KM, Patneau DK, Winters CA, Mayer ML, Buonanno A (1993) Se- lective modulation of desensitization at AMPA versus kainate receptors by cyclothiazide and concanavalin A. Neuron 11:1069-1082.

Partin KM, Patneau DK, Mayer ML (1994) Cyclothiazide differentially modulates desensitization of alpha-amino-3-hydroxy-5-methyl-4-isoaxzolepropionic acid receptor splice variants. Mol Pharmacol 46:129-138.

Partin KM, Fleck MW, Mayer ML (1996) AMPA receptor flip/flop mutants affecting deactivation, desensitization, and modulation by cyclothiazide, aniracetam, and thiocyanate. J Neurosci 16:6634-6647.

Patneau DK, Vyklicky L Jr, Mayer ML (1993) Hippocampal neurons exhibit cyclothiazide-sensitive rapidly desensitizing responses to kainate. J Neurosci 13:3496-3509.

Raman IM, Trussell LO (1992) The kinetics of the response to glutamate and kainate in neurons of the avian cochlear nucleus. Neuron 9:173-186.

Raman IM, Trussell LO (1995) The mechanism of alpha-amino-3-hydroxy5-methyl-4-isoxazolepropionate receptor desensitization after removal of glutamate. Biophys J 68:137-146.

Raman IM, Zhang S, Trussell LO (1994) Pathway-specific variants of AMPA receptors and their contribution to neuronal signaling. J Neurosci 14:4998-5010.

Ravindranathan A, Donevan SD, Sugden SG, Greig A, Rao MS, Parks TN (2000) Contrasting molecular composition and channel properties of AMPA receptors on chick auditory and brainstem motor neurons. J Physiol (Lond) 523:667-684.

Robert A, Irizarry SN, Hughes TE, Howe JR (2001) Subunit interactions and AMPA receptor desensitization. J Neurosci 21:5574-5586.

Rosenmund C, Stern-Bach Y, Stevens CF (1998) The tetrameric structure of a glutamate receptor channel. Science 280:1596-1599.

Rozov A, Jerecic J, Sakmann B, Burnashev N (2001) AMPA receptor channels with long-lasting desensitization in bipolar interneurons contribute to synaptic depression in a novel feedback circuit in layer $2 / 3$ of rat neocortex. J Neurosci 21:8062-8071.

Sätzler K, Sohl LF, Bollmann JH, Borst JG, Frotscher M, Sakmann B, Lubke JH (2002) Three-dimensional reconstruction of a calyx of Held and its postsynaptic principal neuron in the medial nucleus of the trapezoid body. J Neurosci 22:10567-10579.

Scheuss V, Schneggenburger R, Neher E (2002) Separation of presynaptic and postsynaptic contributions to depression by covariance analysis of successive EPSCs at the calyx of Held synapse. J Neurosci 22:728-739.

Schneggenburger R, Meyer AC, Neher E (1999) Released fraction and total size of a pool of immediately available transmitter quanta at a calyx synapse. Neuron 23:399-409.

Stein E, Cox JA, Seeburg PH, Verdoorn TA (1992) Complex pharmacological properties of recombinant alpha-amino-3-hydroxy-5-methyl-4isoxazole propionate receptor subtypes. Mol Pharmacol 42:864-871.

Sun Y, Olson R, Horning M, Armstrong N, Mayer M, Gouaux E (2002) Mechanism of glutamate receptor desensitization. Nature 417:245-253.

Taschenberger H, von Gersdorff H (2000) Fine-tuning an auditory synapse for speed and fidelity: developmental changes in presynaptic waveform, EPSC kinetics, and synaptic plasticity. J Neurosci 20:9162-9173.

Taschenberger H, Leao RM, Rowland KC, Spirou GA, von Gersdorff H (2002) Optimizing synaptic architecture and efficiency for highfrequency transmission. Neuron 36:1127-1143.

Thomson AM (2000) Facilitation, augmentation and potentiation at central synapses. Trends Neurosci 23:305-312.

Trussell LO, Thio LL, Zorumski CF, Fischbach GD (1988) Rapid desensitization of glutamate receptors in vertebrate central neurons. Proc Natl Acad Sci USA 85:4562-4566.

Trussell LO, Zhang S, Raman IM (1993) Desensitization of AMPA receptors upon multiquantal neurotransmitter release. Neuron 10:1185-1196.

Wadiche JI, Jahr CE (2001) Multivesicular release at climbing fiberPurkinje cell synapses. Neuron 32:301-313.

Wang LY, Kaczmarek LK (1998) High-frequency firing helps replenish the readily releasable pool of synaptic vesicles. Nature 394:384-388.

Weber M, Dietrich D, Grasel I, Reuter G, Seifert G, Steinhauser C (2001) 6-Hydroxykynurenic acid and kynurenic acid differently antagonise AMPA and NMDA receptors in hippocampal neurones. J Neurochem 77:1108-1115.

Wong AYC, Graham B, Forsythe ID (2001) Contribution of receptor desensitization to synaptic depression at a glutamatergic synapse. Soc Neurosci Abstr 27:502.9. 